\title{
ESTUDO SOBRE A VISÃO DO CORPO DISCENTE QUANTO ÀS NOVAS METODOLOGIAS DE ENSINO PARA OS CURSOS DE ENGENHARIAS DA UNISALES
}

\section{REVIEW ON THE SIGHT OF THE STUDENTS ON NEW TEACHING METHODOLOGIES FOR UNISALES ENGINEERING COURSES}

\author{
Miriam Aparecida Ignácio de Almeida ${ }^{1^{*}}$ \& Flávio Lúcio Santos de Carvalho ${ }^{2 *}$ \\ ${ }^{12}$ Centro Universitário Salesiano - UniSales. \\ ${ }^{1}$ malmeida@souunisales.com.br ${ }^{2 *}$ fcarvalho@ salesiano.br
}

\section{ARTIGO INFO.}

\section{Recebido em: 12.08.2021}

Aprovado em: 20.09.2021

Disponibilizado em: 02.12.2021

\section{Palavras-chave:}

PBL; Interação, Conhecimentos Acadêmicos, Vivências Práticas, Implementação, Formação Crítica.

\section{KEYWORDS:}

PBL; Interaction, Academic Knowledge, Practical Experiences, Implementation, Critical Training.

\section{RESUMO}

Atualmente pensa-se e se discute muito sobre as novas metodologias de ensino estando elas nas diferentes etapas da educação básica, para que se aprimorem nos alunos: a aquisição dos conhecimentos, a interação e a integração desses conhecimentos com as situações reais de trabalho, onde se aplicam de forma mais assertiva esses conhecimentos, além do afloramento do protagonismo, autoconfiança, empatia e solidariedade e sustentabilidade, ressaltando também todas as demais habilidades e competências que o mercado profissional demanda. Mas, ao mesmo tempo que isso tudo seja instigante e atraente para todo corpo acadêmico, principalmente para corpo discente, é muito assustador e desafiador, pois é tudo novo e diferente do método tradicional de ensino que está sendo utilizado desde o início do processo de transmissão de conhecimento. Tanto para nós, os professores, os alunos, quanto para as instituições, ocorrem dificuldades para adaptação da metodologia tradicional para as novas metodologias. Logo, a proposta deste trabalho é avaliar o sentimento do corpo discente frente à todas mudanças propostas para o sistema de ensino. Foram realizados questionamentos aos estudantes, através de uma pesquisa on line com estes, verificando de forma detalhada, as expectativas, as dúvidas e outras informações quanto a mudança para as novas metodologias de ensino. Os resultados estatísticos mostraram que os estudantes estão cientes que as mudanças são pertinentes em função das novas demandas do mercado, mas conclui-se que ainda se sentem receosos de como estas mudanças estão ocorrendo e se as instituições, o corpo docente e eles próprios estão preparados para tal.

\begin{abstract}
Currently, a lot is thought and discussed about new teaching methodologies, which are in the different stages of basic education, so that they improve in students: the acquisition of knowledge, interaction and integration of this knowledge with real work situations, where this knowledge is more assertively applied, in addition to the emergence of protagonist, self-confidence, empathy and solidarity and sustainability, also emphasizing all the other skills and competences that the professional market demands. But, while this is all exciting and attractive to the entire academic body, especially the student body, it is very scary and challenging, as it is all new and different from the traditional teaching method that has been used since the beginning of the transmission process. of knowledge. Both for us, the professors, the students, and for the institutions, there are difficulties in adapting the traditional methodology to the new methodologies. Therefore, the purpose of this work is to evaluate the feeling of the student body in face of all the proposed changes to the education system. Questions were made to students, through an online survey with them, checking in detail, expectations, doubts and other information regarding the change to new teaching methodologies. The statistical results showed that students are aware that the changes are relevant due to new market demands, but it is concluded that they are still afraid of how these changes are taking place and if the institutions, the teaching staff and themselves are prepared for such.
\end{abstract}




\section{INTRODUÇÃO}

Atualmente tem se pensado e se discutido muito sobre as novas metodologias de ensino estando elas nas diferentes etapas da educação básica, para que se aprimorem nos alunos: a aquisição dos conhecimentos, a interação e a integração desses conhecimentos com as situações reais de trabalho, onde se aplicam de forma mais assertiva esses conhecimentos, além do afloramento do protagonismo, autoconfiança, empatia e solidariedade e sustentabilidade, ressaltando também todas as demais habilidades e competências que o mercado profissional demanda.

Mas, ao mesmo tempo que isso tudo seja instigante e atraente para todo corpo acadêmico, principalmente para o corpo discente, é muito assustador e desafiador, pois é tudo muito novo e diferente do método tradicional de ensino que está sendo utilizado desde o início do processo de transmissão de conhecimento.

Para nós, o corpo docente das instituições de ensino, também é muito difícil realizar as mudanças de métodos de ensino, pois tem-se que quebrar paradigmas em toda a estrutura de ensino, desde seus planos de aula, de ensino e de curso até os procedimentos de aulas expositivas presenciais e/ou não presenciais.

Os alunos também sentem tanto ou mais dificuldades para se adaptarem aos novos métodos de ensino onde eles, durante toda a sua vida estudantil, tiveram seus estudos no método tradicional.

Vale lembrar que com a modernização do mercado, ocorrem necessidades de profissionais com vivências práticas e integradas (conceitos acadêmicos, conhecimentos de vida e estudo de casos práticos) para atender as demandas cada vez mais crescentes desses tipos de profissionais. Mas existem dúvidas se a metodologia tradicional de ensino está ultrapassada, se existe a possibilidade de realizar uma hibridização entre as metodologias tradicional e novas ou ainda a total substituição para a metodologia nova. E o mais importante: como está a expectativa dos alunos quanto essas mudanças.

Logo, a proposta deste trabalho é avaliar o sentimento do corpo discente frente à todas mudanças propostas para o sistema de ensino. E através dos estudos tem-se ainda como objetivos específicos:

- determinar as impressões dos alunos quanto ao ensino utilizando novas metodologias

- verificar os impactos no ensino superior quanto às mudanças de metodologias

- verificar quais fatores influenciam no entendimento e compreensão de forma comparativa das metodologias: nova e tradicional.

- verificar a efetividade da nova metodologia quanto ao índice de progressão dos alunos (aprovação).

Pode-se observar que a principal problemática que foi investigada neste trabalho é a expectativa real dos alunos quanto à nova metodologia de ensino utilizada na instituição para seus cursos superiores.

Vale ressaltar a comparação existente entre os alunos quanto aos métodos de ensino: tradicional, onde ocorre a transmissão de conhecimento professor-alunos; uma forma que considera-se "mesclada", onde professores incorporaram algumas técnicas aprimoradas ou inovadoras na 
Citação (APA): Almeida, M. A. I., de. \& Carvalho, F. L. S., de. (2021). Estudo sobre a visão do corpo discente quanto às novas metodologias de ensino para os cursos de engenharias da UNISALES. Brazilian Journal of Production Engineering, 7(4), 11-22.

metodologia tradicional, tais como: sala invertida (Project or Problem Basead Learning - PBL); gamificação; estudo de casos reais com práticas, dentre outras existentes; e a nova metodologia onde o protagonismo estudantil é a chave para o desenvolvimento profissional e acadêmico.

Importante destacar que independente das metodologias acima citadas, a presença orientadora do corpo docente é imprescindível para o desenvolvimento dos alunos (acadêmico e profissional).

Ao final, ressalta-se que tanto a quantificação das reais expectativas dos alunos quanto a nova metodologia e seus reais impactos na vida acadêmica e profissional, quanto a medição intuitiva da qualidade da nova metodologia influenciando nos mesmos.

\section{REFERENCIAL TEÓRICO}

\subsection{NOVAS METODOLOGIAS}

Nos dias atuais, é visível a redução de oportunidades no mercado para profissionais que não se mantem em constante qualificação acadêmica, técnica, social e crítica (versatilidade, flexibilidade, analítica, estratégia, criatividade, sustentabilidade, vencer diversidades dentre outras). Portanto é vital a importância de se ter como base um ensino preparatório com uma qualidade diferenciada para que o profissional recém formado adentre no mercado de forma segura e assertiva.

E para isso ocorrer, as instituições de ensino superior devem se mostrar mais inclinadas em adequar seus cursos nas novas metodologias onde essas, aprimorem as habilidades e competências já existentes nos estudantes e acrescentem novas, para assim tornar os mesmos em profissionais competitivos visando atender um mercado igualmente competitivo (Macedo et al., 2012).

Ressalta-se a importância de se esclarecer que dentro de um contexto educativo que pessoas competentes nem sempre são pessoas competitivas e vice versa, Pois pessoas competentes apresentam-se capazes em solucionar problemas diversos de forma satisfatória com interações em diversas áreas (técnicas e sociais), o que muitas vezes as tornam competitivas, passando a ter mais facilidades em disputas de espaços de atuação no mercado (Macedo, 2012).

Mas deve destacar que um profissional eficaz é eficiente por consequência, e o contrário não é verdadeiro, logo, não se deve apenas resolver de forma satisfatória e sim resolver de forma eficaz quaisquer problemas demandados.

Quanto as novas metodologias que as instituições de ensino superior (IES) se inclinam para adequar seus cursos, pode-se citar como principais: Metodologia de Projetos e Metodologia de Ensino Baseado em Problemas

- Metodologia ou Método de Projetos (MP) tem como característica a facilidade de aplicação tanto no ciclo básico quanto no ciclo profissional de cursos superiores independente das áreas de atuação, cujo principal objetivo é a vincular os conceitos teóricos com os conceitos práticos para desvendar e resolver problemas propostos. 
Para efetiva aplicação da metodologia acima, o docente propõe a divisão da turma em grupos independente de habilidades individuais que se reúnem para discutir sobre o problema ou situação estudada e a partir disso, propor uma resolução deste.

Vale destacar que os grupos devem propor tais soluções baseando nos conceitos acadêmicos estudados na disciplina em questão. Através desta metodologia os estudantes se aprimoram em se expressar (escrita ou oral) de forma acadêmica e crítica quanto às propostas de resolução dos problemas, demostrando assim iniciativa, protagonismo, criatividade e trabalho em equipe na identificação e resolução do problema.

- Metodologia do Ensino Baseado em Problemas (Project or Problem Basead Learning $P B L)$ propõe-se uma mudança ou uma troca no papel central durante o ensino: do professor para o problema ou situação ou projeto real e este será exclusivamente executado pelos estudantes (seja individual ou coletivamente). Assim, sendo os problemas ou situações reais, estes visam estimular nos discentes, um processo de autonomia quanto a estruturação de seus conhecimentos (integrando conceitos acadêmicos e práticos).

Nessa metodologia se ressalta intensamente caráter multidisciplinar quanto a necessidade de identificar e propor resoluções para os problemas ou situações reais (Macedo, 2012).

Para se ter uma maior assertividade dos grupos de trabalho e assim obter êxito quanto identificar e propor resoluções, estes devem apresentar as seguintes caraterísticas onde o professor, no papel de mediador ou orientador deve identificar e ajudar na composição dos grupos para que sigam os seguintes passos: Criação de um Grupo de Facilitadores da Aprendizagem; Criação de Grupos de Alunos Investigadores, Seleção do problema a ser solucionado, Realização de reuniões dos Grupos de Alunos Investigadores, periódicas e formais, lideradas pelo coordenador do Grupo de Facilitadores,

Portanto, para se obter um corpo discente com aprendizagem de resultados efetivos, é importante ocorra estímulos e motivação entre ele, entre ele e o professor orientador e mediador e entre ele e a instituição. Como os projetos são baseados em situações ou problemas reais, pode ocorrem de forma muito positiva a interação entre os discentes com as comunidades de entorno ou com o mercado demandante das situações ou problemas.

Essas interações e cooperações entre corpo docente, discentes, instituição e mercado (comunidades, empresas e órgãos) são indispensáveis e molas motrizes para o aprimoramento dos conhecimentos e desenvolvimento das habilidades e competências, promovendo assim a consolidação dos discentes em profissionais aptos e competitivos conforme as demandas do mercado e mais ainda: os discentes se tornam continuamente motivados a querer sempre se aprimorarem quanto aos conceitos acadêmicos e também quanto as habilidades sociais, críticas e pensantes, tudo isso de forma autônoma, protagonista e contínua..

\subsection{IMPLEMENTAÇÃO DE UMA NOVA METODOLOGIA}

Atualmente surgem inúmeras propostas e discussões sobre as reformas no ensino superior independente dos cursos, principalmente quando se trata das reformas nos currículos, visando particularmente quanto a inclusão ou utilização de novas metodologias, novas disciplinas, visando uma formação mais humanística para os novos profissionais, principalmente os profissionais da área de exatas e tecnológicas, onde pode-se destacar os engenheiros. 
Citação (APA): Almeida, M. A. I., de. \& Carvalho, F. L. S., de. (2021). Estudo sobre a visão do corpo discente quanto às novas metodologias de ensino para os cursos de engenharias da UNISALES. Brazilian Journal of Production Engineering, 7(4), 11-22.

Realizando análises de forma mais detalhada do momento real das instituições de ensino superior (IES), observa-se que a maior parte dos professores engenheiros se mostram despreparados para formar os novos engenheiros. Isto reflete devido que os professores se formaram no método tradicional que então priorizava-se a transmissão de conhecimento puramente técnico, não utilizando técnicas pedagógicas ou preparação nessa área. Logo, foi se reproduzindo esta metodologia ao longo do tempo, ou seja, focalizando apenas em aulas expositivas com transmissão de conhecimento única e específica pelos professores e os alunos ouvem as instruções repassadas para a resolução de exercícios e problemas propostas (Simon, 2003).

Tendo a tecnologia de modo geral em constante ascendência, acompanhada com o elevados dinamismo e diversidade da informação, torna-se extremamente dificultada para qualquer pessoa ter um conhecimento total para a resolução de quaisquer problemas de variadas complexidades, logo ressaltar-se da importância de se promover a realização de trabalho em equipes especializadas e multidisciplinares.

Observa-se também que nem sempre essa ascendência tecnológica obtida ao longo dos anos, é acompanhada pelos cursos de engenharia das IES e pelo corpo docente, então faz-se necessário constante aprimoramento dos professores, seja na área tecnológica de sua especialidade, seja na área pedagógica.

É notável que para um bom professor de uma determinada área de especialidade, este deve ter total domínio do conteúdo e de suas demais características e especialidades. Contudo, ter este total conhecimento não é simplesmente apresentar facilidades em resolução de exercícios existentes em cada fim de capítulo ministrado. O real conhecer os conteúdos significa em:

- Conhecer os problemas existentes e ao mesmo tempo o contexto no qual o conhecimento científico apresentou em seu desenvolvimento, principalmente, os obstáculos epistemológicos que ocorreram durante o progresso;

- Conhecer quais estratégias metodológicas que foram empregadas nos processos científicos;

- Conhecer as interações que possam existir entre a Ciência / Tecnologia e suas respectivas relações com a sociedade como todo, estando essas associadas ao conhecimento científico;

- Conhecer, pelo menos de forma mais simples, os principais desenvolvimentos científicos mais recentes e as suas perspectivas para a aquisição de uma visão mais dinâmica, e não acabada, da Tecnologia;

- Realizar de forma sistêmica a seleção de conteúdos mais adequados que possam favorecer a visão assertiva da Tecnologia e, paralelamente, sendo esses mais acessíveis e motivadores para os estudantes

Pode-se então afirmar que, além da visão mais abrangente sobre o que seja o total domínio do conteúdo a ser ministrado, também faz-se necessário que se tenha uma formação pedagógica, para que o corpo docente possa sempre propor novas atividades / avaliações / projetos e desafios mais motivadores, interativos e integrados entre casos reais e acadêmicos para os alunos, estabelecendo assim novas metodologias de sala de aula. (Simon, 2003).

Complementando, deve-se ressaltar a importância da mudança de atitude do corpo docente diante às novas metodologias. Pois, citar simplesmente que o professor e a sua prática em sala 
Citação (APA): Almeida, M. A. I., de. \& Carvalho, F. L. S., de. (2021). Estudo sobre a visão do corpo discente quanto às novas metodologias de ensino para os cursos de engenharias da UNISALES. Brazilian Journal of Production Engineering, 7(4), 11-22.

de aula necessitam de modificações sem quaisquer motivações ou explicações embasadas para tal, não o fará mudar.

Logo, faz-se importante que o corpo docente sinta que o processo é assertivo e eficaz, mostrando para si que a ocorrência de insatisfação quanto à insuficiência de resultados dos estudantes obtidos pela não utilização de novas técnicas ou metodologias mais interativas e mais próximas à realidade deles. Ressalta-se também que isso somente será conseguido com o trabalho integrado entre corpo docente, coordenação, gestão pedagógica e a instituição de ensino, visando o aprimoramento dos conhecimentos acadêmicos dos estudantes.

\subsection{FORMAÇÃO CRÍTICA DO ESTUDANTE}

Atualmente, para os docentes de modo geral, é cada vez mais imprescindível o desenvolvimento de competências profissionais no que tange a preparação e a formação dos estudantes para o mercado de trabalho que se apresenta cada vez mais competitivo e demandante de qualificações que vão além das qualificações simplesmente técnicas.

Ou seja, os estudantes devem estar preparados para lidar com as mais diversas situações não técnicas que, muitas vezes, serão mais impactantes na resolução das demandas ou problemas que serão impostos aos mesmos. Situações essas que demandarão senso crítico, análises sociais, estratégias de relação humana, criatividade e protagonismo, dentre outras, e essas muitas dessas competências e habilidades nem sempre são aprendidas corretamente ou nem são aprendidas através de metodologias tradicionais.

Logo, os docentes devem, de forma gradativa, realizar modificações em suas metodologias de ensino, partindo para formas ou metodologias ativas de aprendizagem, aprimorando-se no sentido de aproximar os conhecimentos e conceitos acadêmicos e técnicos com as vivências profissionais, sejam elas vindas dos próprios docentes ou vindas dos estudantes, possibilitando a integração da prática cotidiana com os conceitos acadêmicos.

Ressalta-se que durante o processo de aprendizagem, os docentes que obtiveram resultados mais relevantes no mesmo, ocorreram quando houve uma parceria entre eles e os estudantes, conseguida através de modificações, mesmo que simples, nas metodologias tradicionais de ensino ou utilizando novas metodologias de ensino, onde buscou-se a interação entre prática e teoria, conseguindo assim um maior comprometimento de amos pela disciplina ministrada.

As novas metodologias ou metodologias ativas estimulam os docentes e as instituições a ver com outros olhos o processo de aprendizagem, onde estes se baseiam na interação e utilização de experimentos ou vivências reais com os conceitos acadêmicos para solucionar situações problemas independentes dos contextos aparentes (Borges, 2014).

Para Freire (1996 e 2007), as metodologias ativas ou novas metodologias são importantíssimas. Ele defende essas metodologias promovem a superação de inúmeros desafios, a criatividade na resolução de problemas e a facilidade na construção de novos conhecimentos, tudo isso é possibilitado pelas experiências prévias dos docentes e discentes interagidas com os conceitos acadêmicos e consequentemente das trocas dessas experiências entre eles, proporcionando assim impulsos e motivações para as aprendizagens de todos (docentes e discentes) e ainda aflora nos discentes o protagonismo e a autonomia em aprimorar seus conhecimentos. 
Citação (APA): Almeida, M. A. I., de. \& Carvalho, F. L. S., de. (2021). Estudo sobre a visão do corpo discente quanto às novas metodologias de ensino para os cursos de engenharias da UNISALES. Brazilian Journal of Production Engineering, 7(4), 11-22.

Das metodologias ativas ou novas metodologias se destacam o PBL (Problem or Project Basead Learning) e os Grupos Operativos que promovem a interação, integração das vivências e conhecimentos dos membros das equipes, empatia, protagonismo, criatividade para resolução de problemas e acima de tudo desenvolvendo as habilidades e competências dos estudantes quanto serem mais analíticos, críticos e pensantes.

\section{METODOLOGIA}

A presente pesquisa quanto aos objetivos se enquadrará como sendo de caráter investigativo, porque estudará de forma quantitativa e qualitativa as opiniões dos alunos quanto suas expectativas e impactos em seu desenvolvimento, ao longo do cumprimento do curso superior escolhido.

Em relação à abordagem se classificará como quantitativa, porque o uso de dados numéricos possibilitará o estudo estatístico comparativo das percepções entre as metodologias tradicionais e a nova definida na pesquisa e dos resultados que serão assim obtidos. E qualitativa, que ao fim do estudo, possibilitará a criação de indicadores que, de forma intuitiva, medirá a qualidade do ensino na nova metodologia através dos resultados de aprovação dos alunos.

Para os procedimentos técnicos utilizará o formato de estudo de caso para uma completa abordagem do tema quanto à aplicação de um questionário com perguntas que abrangerá os alunos ingressantes na nova metodologia dos cursos da área de exatas pertencentes aos primeiros períodos.

Ressalta-se que a presente pesquisa terá como base o projeto de implantação da nova metodologia e será realizada no Centro Universitário Salesiano (UniSales), localizado na cidade de Vitória, no estado do Espírito Santo, durante o período de março de 2018 a setembro de 2020.

A pesquisa terá o seu início através de uma revisão bibliográfica com o objetivo de levantar informações sobre os resultados obtidos e as técnicas utilizadas. Após, será realizada uma coleta de dados numéricos através de aplicação de um questionário contendo perguntas para que os alunos exponham suas expectativa e opiniões.

A seguir, serão coletados os dados através de questionário, onde será usado como ferramentas para análises softwares estatísticos (SPSS, Microsoft Excel e outros) para construção de tabelas, gráficos e realização de teste estatísticos, que assim pode-se extrair conclusões como os alunos sentem em relação as metodologias, além das possibilidades de comparações dos resultados entre elas.

Como consequência, a possibilidade de criação de indicadores de qualidade que retratarão a influência da nova metodologia no processo acadêmico e profissional dos alunos como também a possibilidade de demonstrar a eficiência dela no aprimoramento dos alunos, tornando-os mais protagonistas, participativos, críticos e pensantes.

Como resultado, espera-se obter informações que demonstrarão de forma comparativa as metodologias, nas perspectivas dos alunos visando assim a ciência do corpo docente quanto às necessidades de aprimoramento do conhecimento e aplicação da nova metodologia, realizando assertivamente o ensino das disciplinas existentes em cada período do curso para os alunos. 


\section{RESULTADOS}

Após a realização do questionário via on line, houve a seleção e análise dos dados onde foram separados por cursos e por alunos.

Todas as informações foram tabuladas pelos softwares estatísticos: SPSS e Microsoft Excel, onde estão mostrados nos gráficos e tabelas comparativas entre as metodologias nova (baseada em Metodologia ou Método de Projetos - MP ou Metodologia do Ensino Baseado em Problemas - Project or Problem Basead Learning - PBL, tendo como foco o protagonismo do aluno quanto ao busca do conhecimento e aprendizado) e tradicional (baseada em exposição de conhecimentos e conteúdos centralizado no professor), onde todas as fontes são dos próprios autores.

De 56 alunos que participaram da pesquisa:

- 51,8\% Engenharia da Produção,

- $23,2 \%$ Engenharia Civil,

- $10,7 \%$ Engenharia da Computação,

- 8,9\% Administração,

- 5,4\% Engenharia Elétrica,

Do total foram: 67,9\% são homens e 64,3\% têm 18 a 23 anos e 3,6\% têm 38 anos ou mais.

Com relação à expectativa ao estudo da Nova Metodologia, 28,6\% responderam que é muito boa e excelente e 37,5\% responderam que é indiferente e baixa, de acordo com a Tabela 1.

Deve-se ressaltar que a instituição deva realizar estudos para verificar como reverter tal índice quanto a expectativa dos discentes, que se mostra em baixa, pois isso pode afetar e muito a continuidade dos mesmos na instituição, como também pode afetar o número de novas entradas de discentes.

Tabela 1. Distribuição de frequências segundo a expectativa.

\begin{tabular}{ccc}
\hline Expectativa quanto ao estudo na nova metodologia & $\mathbf{N}^{\mathbf{a}}$ de alunos & $\mathbf{\%}$ \\
\hline Indiferente & 5 & 8,9 \\
Baixa & 16 & 28,6 \\
Satisfatória & 19 & 33,9 \\
Muito Boa & 10 & 17,9 \\
Excelente & 6 & 10,7 \\
\hline Total & $\mathbf{5 6}$ & $\mathbf{1 0 0 , 0}$ \\
\hline
\end{tabular}

Quanto a dificuldade na nova metodologia implantada no Centro Universitário Salesiano, $17,9 \%$ responderam que é alta (muita), 46,4\% que é média e 35,8\% disseram que é baixa, nenhuma e indiferente (Gráfico 1). 
Citação (APA): Almeida, M. A. I., de. \& Carvalho, F. L. S., de. (2021). Estudo sobre a visão do corpo discente quanto às novas metodologias de ensino para os cursos de engenharias da UNISALES. Brazilian Journal of Production Engineering, 7(4), 11-22.

Gráfico 1. Dificuldade sentida na nova metodologia implantada no Centro Universitário Salesiano

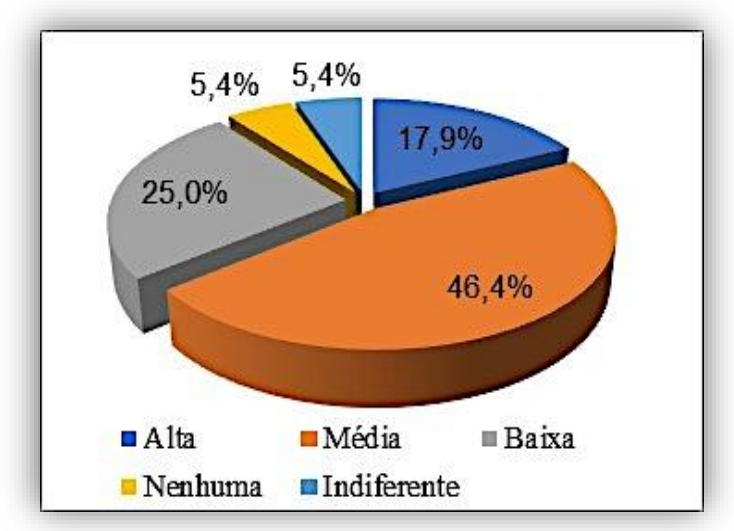

Quanto ao uso de nova metodologia na graduação 73,2\% dos alunos acharam valido o uso; $57,1 \%$ responderam que a nova metodologia facilitou seu modo de estudar; $73,2 \%$ observaram uma maior interação entre eles; 76,8\% observaram uma maior interação entre os alunos e os professores (Gráfico 2).

Gráfico 2. Uso da nova metodologia na graduação

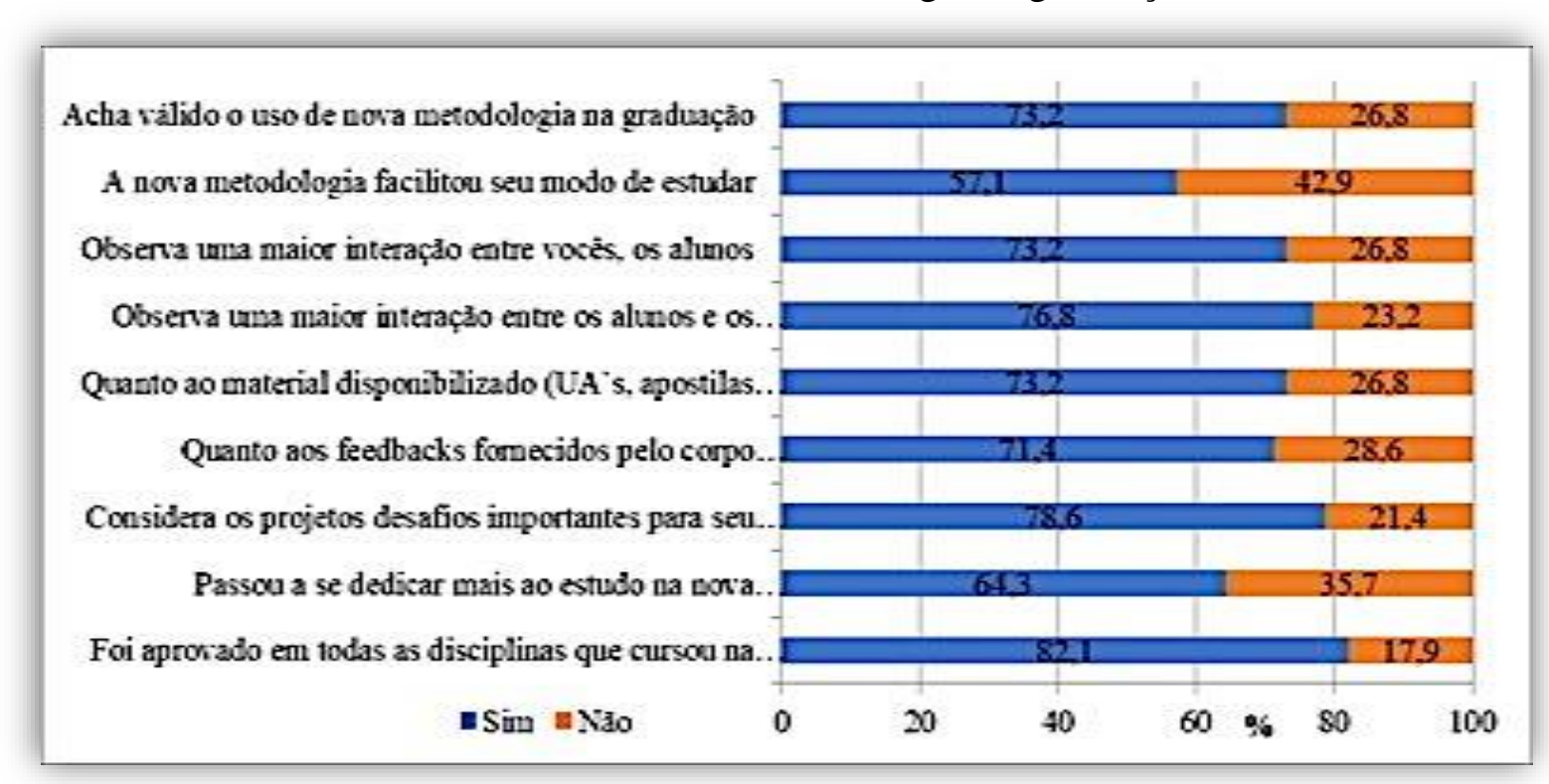

Em relação à comparação entre os métodos tradicional e novo, observa-se que $62,5 \%$ dos alunos responderam que a nova metodologia será o melhor método para sua formação profissional e $7,1 \%$ ficam em dúvidas, tanto que escolheram as duas metodologias e 57,1\% responderam que a nova metodologia facilita a dedicação ao estudo. Quanto ao grau de dedicação ao estudo, independente da metodologia empregada, $53,6 \%$ dos alunos responderam que o grau é médio e $1,8 \%$ responderam que é baixo (Tabela 2 ).

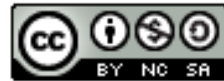


Tabela 2. Distribuição de frequências segundo a dedicação.

\begin{tabular}{ccc}
\hline $\begin{array}{c}\text { Grau de dedicação ao estudo, independentemente da } \\
\text { metodologia de estudo empregada pela instituição }\end{array}$ & $\mathbf{N}^{\mathbf{a}}$ de alunos & $\boldsymbol{\%}$ \\
\hline Alto & 25 & 44,6 \\
Médio & 30 & 53,6 \\
Baixo & 1 & 1,8 \\
\hline Total & $\mathbf{5 6}$ & $\mathbf{1 0 0}$ \\
\hline
\end{tabular}

Com relação à quantidade disciplinas que os alunos foram matriculados na nova metodologia, 48 foram matriculados em 4 e 5 disciplinas, representando $85,7 \%$ e somente 2 se matricularam em 2 disciplinas, representando $3,6 \%$.

Quanto ao nível de aprendizado utilizando a nova metodologia, observa-se o seguinte:

- 11 alunos $(19,6 \%)$ responderam que o nível de habilidade/conhecimento no início do curso foi muito bom e excelente e 14 alunos $(25,0 \%)$ responderam que foi fraco;

- 19 alunos $(33,9 \%)$ responderam que o nível de habilidade/conhecimento no fim das disciplinas foi muito bom e excelente e 11 alunos $(19,6 \%)$ responderam que foi fraco;

- 23 alunos $(41,0 \%)$ responderam que o nível de habilidade/conhecimento exigido para concluir as disciplinas foi muito bom e excelente e 10 alunos $(17,9 \%)$ responderam que foi fraco;

- 22 alunos $(39,2 \%)$ responderam a contribuição das disciplinas para habilidade/conhecimento foi muito bom e excelente e 10 alunos (17,9\%) responderam que foi fraco (Tabela 3 ).

Com relação quantidade de disciplinas que os alunos ficaram pendentes na nova metodologia, $82,1 \%$ não ficaram em nenhuma e 17,9\% ficaram em duas, três ou mais disciplinas.

Tabela 3. Distribuição de frequências segundo o nível de aprendizado

\begin{tabular}{cccccc}
\hline $\begin{array}{c}\text { Nível de aprendizado utilizando } \\
\text { a nova metodologia }\end{array}$ & Fraco & Moderado & Satisfatório & Muito bom & Excelente \\
\hline $\begin{array}{c}\text { Nível de } \\
\text { habilidade/conhecimento no } \\
\text { início do curso } \\
\text { Nível de }\end{array}$ & $14(25,0 \%)$ & $17(30,4 \%)$ & $14(25,0 \%)$ & $7(12,5 \%)$ & $4(7,1 \%)$ \\
$\begin{array}{c}\text { habilidade/conhecimento no fim } \\
\text { das disciplinas } \\
\quad \text { Nível de }\end{array}$ & $11(19,6 \%)$ & $9(16,1 \%)$ & $17(30,4 \%)$ & $11(19,6 \%)$ & $8(14,3 \%)$ \\
$\begin{array}{c}\text { habilidade/conhecimento } \\
\text { exigido para concluir as } \\
\text { disciplinas }\end{array}$ & $10(17,9 \%)$ & $10(17,9 \%)$ & $13(23,2 \%)$ & $14(25,0 \%)$ & $9(16,0 \%)$ \\
$\begin{array}{c}\text { Contribuição das disciplinas } \\
\text { para habilidade/conhecimento }\end{array}$ & $10(17,9 \%)$ & $10(17,9 \%)$ & $14(25,0 \%)$ & $11(19,6 \%)$ & $11(19,6 \%)$ \\
\hline
\end{tabular}

A respeito do corpo docente, observa-se que $62,5 \%$ responderam que concordam e concordam plenamente que o professor foi um orientador/mediador eficiente, 57,1\% responderam que concordam e concordam plenamente que as orientações foram claras e assertivas, $71,4 \%$ responderam que concordam e concordam plenamente que o professor estimulou o interesse dos alunos, 71,4\% responderam que concordam e concordam plenamente que o professor usou bem o tempo durante as aulas, $76,7 \%$ responderam que concordam e concordam plenamente que o professor foi acessível e prestativo, 62,5\% responderam que concordam e concordam plenamente que as avaliações foram assertivas quanto aos conteúdos abordados (Tabela 4). 
Citação (APA): Almeida, M. A. I., de. \& Carvalho, F. L. S., de. (2021). Estudo sobre a visão do corpo discente quanto às novas metodologias de ensino para os cursos de engenharias da UNISALES. Brazilian Journal of Production Engineering, 7(4), 11-22.

Tabela 4. Distribuição de frequências segundo o corpo docente

\begin{tabular}{cccccc}
\hline Sobre o Corpo Docente & $\begin{array}{c}\text { Discordo } \\
\text { Totalmente }\end{array}$ & Discordo & Não sei & Concordo & $\begin{array}{c}\text { Concordo } \\
\text { Plenamente }\end{array}$ \\
\hline $\begin{array}{c}\text { O professor foi um } \\
\text { orientador/mediador eficiente } \\
\text { As orientações foram claras e }\end{array}$ & $2(3,6 \%)$ & $6(10,7 \%)$ & $12(21,4 \%)$ & $29(51,8 \%)$ & $7(12,5 \%)$ \\
$\begin{array}{c}\text { assertivas } \\
\text { O professor estimulou o interesse }\end{array}$ & $1(8,9 \%)$ & $7(12,5 \%)$ & $12(21,4 \%)$ & $26(46,4 \%)$ & $6(10,7 \%)$ \\
$\begin{array}{c}\text { dos alunos } \\
\text { O professor usou bem o tempo } \\
\text { durante as aulas }\end{array}$ & $5(8,9 \%)$ & $2(3,6 \%)$ & $13(23,2 \%)$ & $26(46,4 \%)$ & $14(25,0 \%)$ \\
$\begin{array}{c}\text { O professor foi acessível e } \\
\text { prestativo }\end{array}$ & $4(7,1 \%)$ & $1(1,8 \%)$ & $8(14,3 \%)$ & $32(57,1 \%)$ & $11(19,6 \%)$ \\
\hline $\begin{array}{c}\text { As avaliações foram assertivas } \\
\text { quanto aos conteúdos abordados }\end{array}$ & $4(7,1 \%)$ & $4(7,1 \%)$ & $13(23,2 \%)$ & $23(41,1 \%)$ & $12(21,4 \%)$ \\
\hline
\end{tabular}

Com relação às disciplinas na Nova Metodologia, 51,7\% responderam que concordam e concordam plenamente que os objetivos foram claros e 14,3\% responderam que não sabem, $62,5 \%$ responderam que o conteúdo foi organizado e bem planejado e $12,5 \%$ responderam que não sabem, $57,1 \%$ responderam que a carga horária foi apropriada e 17,9\% responderam que não sabem, 69,6\% responderam que as disciplinas foram organizadas para permitir a participação de todos os alunos (Gráfico 3).

Gráfico 3. Disciplinas na Nova Metodologia

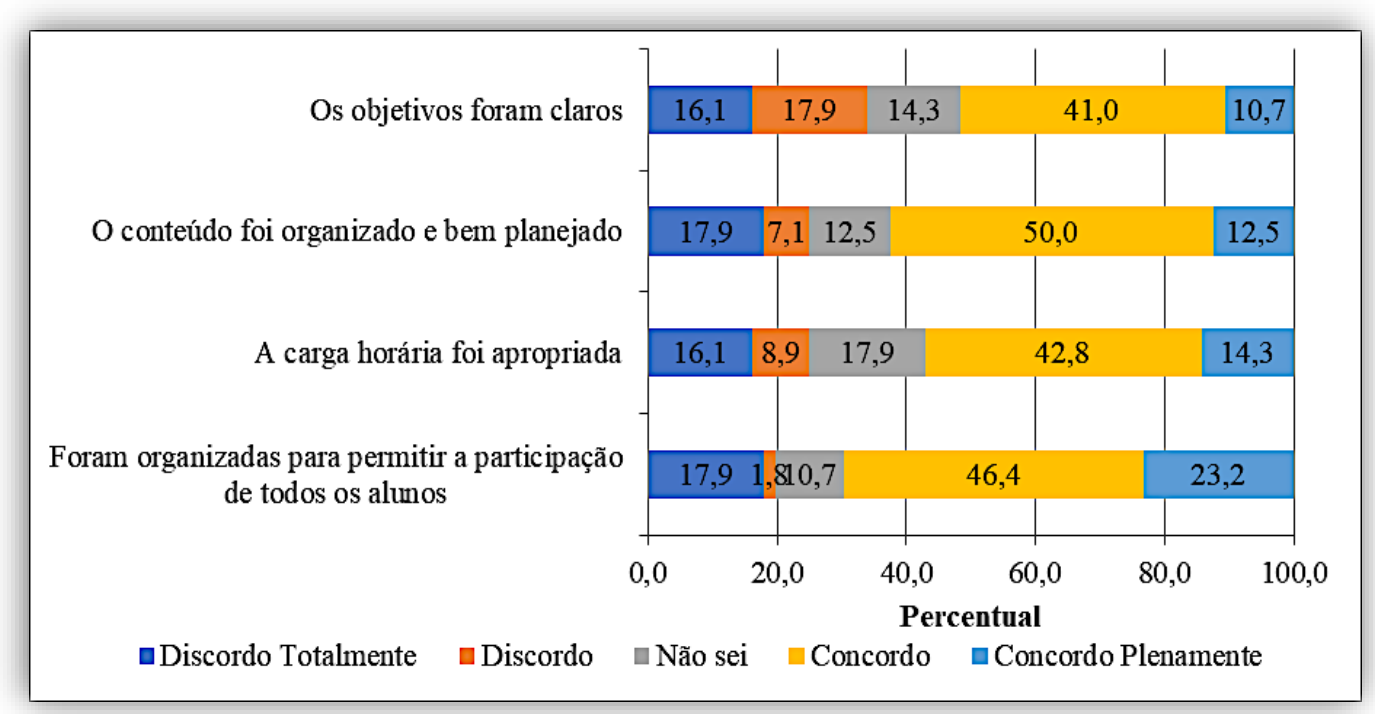

Na pesquisa foi perguntado aos alunos quais os aspectos que eles acharam que foram mais uteis ou valiosos nesta nova metodologia, portanto 42 citaram os seguintes aspectos (transposição do texto de forma autêntica dos alunos):

- A utilização da prática para o mercado de trabalho;

- Maior entendimento, maior clareza e praticidade;

- A interação entre os alunos e aulas dinâmicas;

- Responsabilidade, dedicação, inovação, prática e segurança;

- Estudo mais aprofundado; 
Citação (APA): Almeida, M. A. I., de. \& Carvalho, F. L. S., de. (2021). Estudo sobre a visão do corpo discente quanto às novas metodologias de ensino para os cursos de engenharias da UNISALES. Brazilian Journal of Production Engineering, 7(4), 11-22.

- Trabalhar em grupo;

- A interação com os colegas e a forma de ensinar com as ua's;

- Interação entre os alunos e parte prática;

- Melhor conhecimento e vontade de saber mais das coisas através de pesquisas;

- O incentivo para a busca por conhecimento;

- A necessidade de adaptação e responsabilidade própria para agir;

- O aprendizado eficiente apresentado nesta metodologia;

- Os desafios e projetos propostos;

- Adequação com a era digital; o conteúdo das ua's;

- Os temas dos projetos abordados,

- As interações diretas com os professores,

- As interações com os colegas de classe e as formas de interação com a instituição;

- Nenhum aspecto.

Na pesquisa foi perguntado aos alunos sugestões para a nova metodologia, portanto 37 citaram os seguintes aspectos (transposição do texto de forma autêntica dos alunos):

- Suporte de internet melhor para as aulas online;

- Mais aulas práticas em laboratórios, aulas de campo, visitas técnicas que não ocorreram, equipamentos tecnológicos dentro de sala;

- Mais tempo para as matérias, mais cobrança ao aluno, mais parte teórica, mais provas e menos trabalhos, pois acaba que uns levam outros "nas costas", mais listas de exercícios para os alunos fazerem e entenderem o conteúdo;

- Planejar melhor a entrega dos exercícios;

- Melhore nos métodos avaliativos com notas, auxiliar alguns alunos com maior dificuldade, aperfeiçoar os canais de comunicação, guia nos portais para esclarecimento de dúvidas em relação ao sistema no portal, disponibilizar salas para montar grupos de estudos online;

- Os professores possam trazer empresas para a realização de pequenos estudos de casos como atividades, ao invés de deixar apenas para os desafios ou o trabalho final;

- Aplicar desafios que seja de fácil entendimento, mas sem mudar o padrão de desafios, pois no $3^{\circ}$ período eram desafios trimestrais, agora no $4^{\circ}$ período são todos os meses o que prejudicou a vida acadêmica, parem de usar os alunos como projeto piloto;

- Planejar melhor a entrega dos exercícios;

- Opção do aluno escolher qual metodologia gostaria de continuar seus estudos na instituição;

- Não tenho sugestão, pois prefiro o modelo tradicional de estudo;

- Maior interação do professor para auxiliar no protagonismo dos alunos;

- Mesclar os ensinamentos do professor na sala de aula no qual o professor explica a matéria e separa metades das aulas para utilizar as novas metodologias, na resolução de trabalhos e desafios;

- Mais aulas práticas em laboratórios, aulas de campo, visitas técnicas que não tivemos até agora, equipamentos tecnológicos dentro de sala;

- Não existir, não estou aprendendo nada;

- Explicações demonstrativas da matéria passada;

- Acho que os desafios podiam ser mais bem explicados em algumas disciplinas.

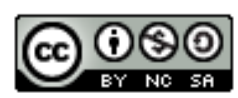


Citação (APA): Almeida, M. A. I., de. \& Carvalho, F. L. S., de. (2021). Estudo sobre a visão do corpo discente quanto às novas metodologias de ensino para os cursos de engenharias da UNISALES. Brazilian Journal of Production Engineering, 7(4), 11-22.

\section{CONSIDERAÇÕES FINAIS}

A pesquisa realizada com os alunos pôde verificar que $28,6 \%$ dos alunos têm muito boa e excelente expectativa quanto à nova metodologia, sendo essa baseada em Metodologia ou Método de Projetos - MP ou Metodologia do Ensino Baseado em Problemas - Project or Problem Basead Learning - PBL, e também verifica-se que eles validam $(73,2 \%)$ o uso da nova metodologia na graduação, mas sentem alta ou média dificuldade na pratica usando a nova metodologia (64,3\%), com a nova metodologia os alunos perceberam que houve uma maior interação entre eles e também perceberam que os desafios propostos nas disciplinas são importantes para o seu desenvolvimento acadêmico e profissional.

Verifica-se que a maioria $(62,5 \%)$ concorda que a nova metodologia é importante para a sua vida profissional, mas muitos alunos relataram que precisam ter mais aulas práticas nos laboratórios, aulas de campo e visitas técnicas para realmente aderirem em prática a proposta da nova Metodologia implantada na UniSales.

Ressalta-se a necessidade de realizar um estudo futuro para melhoria do índice de expectativas positivas dos discentes frente as novas metodologias, é importante que este seja realizado em conjunto: instituição, gestão acadêmica corpo docente e demais pessoas e parcerias (empresas, órgãos públicos e quem sabe comunidades do entorno).

A pesquisa foi feita direcionada para os cursos de Engenharia, mas para trabalhos futuros pode ser realizada também para todos os cursos da UniSales.

\section{REFERÊNCIAS}

Borges, T. S. \& Alencar, G. (2014). Metodologias Ativas Na Promoção Da Formação Crítica Do Estudante: O Uso Das Metodologias Ativas Como Recurso Didático Na Formação Crítica Do Estudante Do Ensino Superior. Cairu em Revista. 3(4), 19-143 , ISSN 22377719.

Ferreira, R. S. (1999). Tendências curriculares na formação do engenheiro do ano 2002. In Linsingen, I. von et al. Formação do engenheiro. Florianópolis: EDUFSC. 9,p. 129-142.

Freire, P. (1996). Pedagogia do Oprimido. São Paulo, Editora Paz e Terra.

Freire, P. (2007). Pedagogia da Autonomia. São Paulo, Editora Paz e Terra.

Libaneo. J. C. (2020). O ensino de graduação na universidade: a aula universitária. Recuperado de www.ucg.br/site_docente/edu/libaneo/pdf/ensino.pdf

Macedo, R. J., Duarte, M. A., \& Teixeira, N. G. (2012). Novas Metodologias de Ensino e Aprendizagem Aplicadas ao Curso de Engenharia Elétrica: O Foco do Ensino No Século XXI. Artigo COBENGE 2012

Mercado, L. P. L. (2002). Novas tecnologias na educação: reflexões sobre a prática. UFAL, $207 \mathrm{p}$.

Ramos, A., Delgado, F., Afonso, P., Cruchinho, A., Pereira, P., Sapeta, P., \& Ramos, G. (2003). Implementação de novas práticas pedagógicas no ensino superior. artigo. Revista Portuguesa de Educação, 26(1). ISSN 0871-9187.

Ribeiro, L. R. C. et al., (2003). Uma experiência com a PBL no ensino de engenharia sob a ótica dos alunos. São Paulo: COBENGE, 2003.

Simon, F. O., Sanches, C. G., Silva, D., Barros, J. F., Almeida, N., \& Veraszto, E. V. (2003). Análise crítica da implementação de novas metodologias de ensino. Artigo COBENGE 2003.

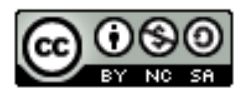

